\title{
20
}

\section{Transforming a Teaching Culture Through Peer Mentoring: Connecticut College's Johnson Teaching Seminar for Incoming Faculty}

\author{
Michael Reder, Eugene V. Gallagher \\ Connecticut College
}

This chapter describes a yearlong seminar focused on teaching that is offered to all incoming tenure-track faculty at Connecticut College, a small residential libcral arts college. This seminar is distinctive because it is facilitated by second-and third-year faculty. We argue that this peer-mentoring model has three distinct benefits. First, it avoids many of the pitfalls identified with traditional one-onone mentoring. Second, it addresses the distinctive challenges that faculty face at small colleges. Third, it provides a strong base for faculty to pursue the scholarship of teaching and learning (SoTL). We believe that our peer-mentoring model may well be adaptable to different types of institutions. As evidence of our faculty's newfound engagement in SoTL, where previously little or no critical attention was paid to teaching, program participants have made presentations and run workshops on our own campus and at regional and national conferences, have begun to serve on teaching committees within their disciplinary organizations, and have gone on to publish their pedagogical work in a varicty of national publications, both disciplinary and teaching focused.

the Connecticut College Center for Teaching and Learning (CTL), we
started out with the simple idea of giving more than mere lip service to
the notion of the importance of teaching. Part of the original mandate of the
CTL was to support new faculty-a straightforward if potentially paternalistic 
idea. Although the amount and kind of teaching experiences that incoming faculty bring to Connecticut College vary widely, all faculty face the challenge of teaching in a new environment. New faculty have undergone graduate training at large research universities where the type of teaching demonstrated is not necessarily a good fit in the classrooms of small liberal arts institutions. They may be assigned to teach new and unfamiliar courses. There are also new contexts for their work in the classroom, in their departments, and in the college as a whole.

Since 1998, Connecticut College's Christian A. Johnson Teaching Seminar for Incoming Faculty has been supporting faculty in their roles as teachers, scholars, and community members and has addressed those challenges that face new faculty members through a regularly scheduled sequence of meetings.' Our peer-mentoring model uses second- and third-year faculty as well as the CTL's director and faculty fellow to lead monthly seminars on topics such as local campus culture, course design, active learning, learning styles, diversity and power in the classroom, and balancing the many demands of campus life. Cohorts of new faculty-no longer isolated in their buildings and departments-are forming bonds and transforming the teaching culture at our college. Teaching has become something not only valued but also shared and discussed.

After describing the basics of our yearlong seminar, we will discuss the ways in which our peer-mentoring model addresses many of the challenges new faculty face at smaller institutions. We will then describe how our peerbased, multi-cohort approach has had unintended consequences in terms of both collaboration among faculty and their participation in the scholarship of teaching and learning (SoTL). We then offer our recommendations for promoting faculty work on teaching and SoTL, especially at a small college, and evidence of the success of our program.

The first session of the Johnson Seminar is usually held on the Friday of the week before classes begin, at the end of the college's official orientation for new faculty. We meet in the morning for breakfast, and our session begins with a nuts-and-bolts question-and-answer period that addresses any concerns that seminar members might have about teaching at Connecticut College. These questions typically range from the specific (What are the required office hours? What should my students call me? What should I call my students?) to the overarching and philosophical (What are student expectations about grades and workloads? What is it like to be a faculty member of color in a mostly white classroom?). Because the session is facilitated by second- and third-ycar faculty who have themselves recently made the transition to teaching at the college, they can share their own local experiences, challenges, and successes. Having 
second-and third-year faculty present-usually in numbers close to those of first-year faculty-also provides a larger range of experiences to share, both in terms of disciplinary focus, faculty identity, and teaching styles.

After the discussion, we break into small groups and read drafts of each other's syllabi. We ask faculty to review these syllabi as both teachers of other classes and as potential students. Is everything clear? Is the timing and amount of work reasonable (for both the faculty member and his or her students)? Each faculty member takes a turn presenting his or her own syllabus to the group, expressing concerns and answering questions. After about an hour we then reconvene as a large group and share best practices for syllabi: lateness and attendance policies we liked, the idea of being as explicit as possible in terms of learning goals and requirements, and other issues faculty might want to consider when constructing their syllabi. From our accumulated experience, we are convinced that a careful review of a syllabus can be the single most effective tool for bringing to light someone's fundamental assumptions about both the process of teaching and the nature of the subject. ${ }^{2}$

To end the morning, we talk about ideas for the first day of class: the importance of students getting to know each other, how to situate yourself and establish credibility (especially as a woman or nonmajority faculty member), a variety of activities to introduce students to the subject and to each other. We believe that faculty should do more on the first day of class than merely read through the syllabus. Establishing expectations and a general tone for a class is essential, and ideally each student should do a little bit of what he or she will be expected to do throughout the semester: from talking with each other and participating in discussion to engaging in small group work, inclass writing, and careful listening. We end the morning with a brief, written survey of possible topics for our upcoming monthly lunchtime meetings and workshops, and then as a group go for lunch to a local restaurant where our conversations continue.

There are several features of this first seminar that set the tone for the rest of the year. First, the entire day is collaborative, with both experienced facilitators and first-year faculty working together. The open format of the seminar clearly sends the message that "We are here to help and learn from each other," rather than "This is what you need to do." ${ }^{3}$ Second, spending an entire day talking about teaching sends a powerful message that Connecticut College not only values teaching but also thinks of it as something that is shared and practiced critically. We have found that this introduction to teaching at the college has created a strong foundation for faculty to go on to engage in SoTL. Finally, as we discuss later, this model of peer mentoring creates a strong nexus of support for faculty that crosses both cohorts and disciplinary boundaries. 


\section{Peer Mentoring and the Specific Challenges of Institutional Type}

The shortcoming of traditional one-on-one mentoring, where one member of the pair is a protégé and the other is a more senior mentor, have been well documented by Boice $(1991,1992)$ and others (Otto, 1994). Traditional mentoring, in the words of Boice (1992), provides "little more than socioemotional support" (p. 120). Such mentoring, Boice (1992) believes, does "little or nothing to extend the social networks of new faculty to students" (p. 121), does not directly address the improvement of teaching, and is narrow and passive, in that it can often put new faculty only on the receiving end of advice. Even taking into account the research that suggests strategies for increasing the effectiveness of such mentoring relationships, such as group meetings, pairing faculty from different departments, and written obligations (Boice, 1992), mentoring pairs are limited in their ability to create a nexus of supportive relationships within and across cohorts and departments. Such interdepartmental connections are particularly important on a small college campus, where departments range in size from 2 to 10 members, and a newly hired faculty member may be the only untenured member in his or her department.

Although the recent research into self-directed learning communities reveals that such groups successfully connect individual faculty to larger groups of faculty outside their departments, these communities, such as Cox (2001) describes, are not focused on new faculty. The most recent adaptations of faculty learning communities, such as Otterbein College's program for first-year faculty, may apply the idea of learning communities to new faculty but do so only to a single cohort and therefore do little to connect faculty across cohorts (Fayne \& Ortquist-Ahrens, 2006). By involving recently hired cohorts of faculty we promote continuing relationships among them and their most recently hired colleagues. We believe that the power in our arrangement is that second-and third-year faculty are intimately involved in guiding first-year faculty-not as wizened mentors with all the answers, but as empathetic peers who have slightly more experience at the institution. We have found, however, that the second-and third-year faculty often get as much from their continued participation in the Johnson Seminar, particularly in the area of classroom practice and course design, as their first-year colleagues. Indeed, during the first few years of our seminars we would ask only two or three first-year faculty to return the following year to help facilitate the group, until we began to hear from second-year faculty not returning to the seminar that they were still encountering challenges and having successes they would like to share and that they missed participating. In subsequent years we made an 
open call for returning participants, and in most years $80 \%-90 \%$ of the firstyear faculty return for a second year. ${ }^{4}$

Boice (1992) has recognized the potential effectiveness of what we term peer mentoring, stating that mentoring programs will fare better if they break the traditional pairing of a senior mentor with a protégé in the same discipline, noting that "junior mentors work just as well" (p. 119). Wheeler and Wheeler (1994) suggest what they term colleague mentoring for mid-career faculty, but we believe that early-career faculty across cohorts are also well situated to mentor each other, and that peer mentoring can be especially effective at small colleges, where most faculty must make the transition from their training at a large university to the distinctive culture of a small college.

Small liberal arts colleges in particular typically want to be known for the quality of their classroom teaching, and they often attract faculty who share the tacit belief that teaching is the sine qua non of their faculty role. Yet simply valuing good teaching does not necessarily lead to good teaching. "Faculty need to be critical practitioners of their craft and critical practitioners share, discuss, and analyze their classroom practices" (Holmgren, Mooney, \& Reder, 2005). By immediately devoting time and energy to the discussion of teaching - before classes even begin-Connecticut College sends the message to all its new faculty that teaching is not only something valued, but something that is actively discussed and institutionally supported.

The Johnson seminar also shows that the college devotes resources and energy toward supporting recently hired faculty members. For a new faculty member, many factors make the first year at a small college challenging, including learning about the local characteristics of the teaching and learning environment, fitting into a department, and balancing the demands of teaching, research, student contact, service, and institutional governance. In our experience, many new faculty find a small school's institutional community-identified by Rice, Sorcinelli, and Austin (2000) as a positive trait of small colleges-both limiting and frustrating. For example, the residential nature of such schools can make new faculty feel the demands of their jobs 24 hours a day, 7 days a week. Because many small schools are church affiliated, dealing with an institution's religious traditions can also pose special challenges. Diversity - among faculty, students, and even disciplines-is also a distinct issue on small college campuses. Small departments-where new faculty are often hired to diversify course offerings or the faculty itself-can quickly become oppressive if "mentoring" by more senior colleagues takes the form of micromanaging course content or teaching styles.

Faculty also need to discover the distinctive expectations of their particular students and calibrate their own expectations at least partially in response 
(Smith \& Kalivoda, 1998). They must learn to work with new colleagues who manifest varying degrees of engagement in their own work and different degrees of empathy for the situation of beginning faculty members. There are myriad aspects of a new setting that even the most experienced faculty member needs to discern and adjust to. As Hall (2002) notes, "Our careers are largely local" (p. 70), and one key to a faculty member's success is understanding institutional expectations (Menges \& Associates, 1999). Hall also argues that a faculty member's happiness largely depends on his or her own "behaviors, attitudes, and interactions within the communities of our departments, colleges, and universities" (p. 73), and that overall success "derives from our understanding of local history and the genesis of local behaviors" (p. 77). At a small institution these issues can be pressurized: The local is more local, so to speak, and the small size of the faculty means there is less diversity and potentially fewer places in which to find one's niche. The Johnson Seminar, by creating a safe space in which faculty can explore these many issues during their early careers, helps faculty find a nexus of support and reliable sources of information about the challenges they face.

Additionally, beginning faculty face both explicit and implicit expectations for successful and productive disciplinary scholarship, and after their first year they are quickly tapped for various kinds of service. In many ways the most valuable commodity for a beginning faculty member-even more than for their senior colleagues-is time. But time often seems to be in very short supply (Menges, 1996). Even for those who have some familiarity with the current scholarly discussion of teaching and learning, it can be hard to imagine how they will be able to carve time out of their schedule to focus on their teaching. One overall effect of the seminar's conversations, however, has been to encourage an early and more sustained engagement with teaching as a critical practice, and this has had the indirect effect of creating a strong foundation for the scholarship of teaching and learning.

\section{Promoting the Scholarship of Teaching and Learning: Creating an Atmosphere of Teaching as Critical Practice}

In spite of the increasing attention that has been devoted to the scholarship of teaching and learning over the past 10 or 15 years, relatively few faculty members are interested pursuing it, especially in their early careers. Their explicit resistance is often based on the amount of time they fear they would have to invest, a professed unfamiliarity with this new field of research, the need to attend to other more pressing disciplinary commitments, and a general disdain 
for the field of education. Teaching-related scholarship may carry with it lower status and rewards than disciplinary scholarship, which may also account for resistance (Wright, 1995). Sometimes more forthright objections take the form of confident proclamations that one's own teaching is very successful and therefore needs no further attention. On many campuses it is difficult to create and maintain a culture that values sustained and systematic examination of teaching practices. This is particularly true at small liberal arts colleges, where "good teaching" is usually thought of as a given. The Johnson Seminar explores issues related to SoTL, sometimes directly and sometimes more indirectly, in the context of teaching at Connecticut College. It also aims to show the various ways in which engagement in SoTL might matter for individuals.

We will use definitions of SoTL given by two of its best-known advocates as reference points. Boyer (1990) argues, "The work of the professor becomes consequential only as it is understood by others.... Pedagogical procedures must be carefully planned, continually examined, and relate directly to the subject taught" (pp. 23-24). Building on this notion, Shulman offers a definition, first asking, "What would be a thumbnail explanation of what we mean by the scholarship of teaching?" He replies,

The scholarship of teaching is a way of capturing teaching in a manner that makes it possible for others both to review it critically and to build on it themselves. That's all that scholarship is. What is teaching? Teaching is more than talking to students and listening to them respond. Teaching is a process of design, interaction, evaluation, and redesign. Put those two together and you have the scholarship of teaching. (Carnegie Foundation for the Advancement of Teaching, 1999)

Using these two definitions makes SoTL sound like a rather straightforward undertaking: Basically it is about shared critical practice, taking teaching and student learning as objects worthy of study and discussion among professionals. Put most simply, the scholarship of teaching and learning is about examining, refining, and promoting effective teaching and learning.

The Johnson Seminar, then, begins to connect faculty with SoTL from its first meeting, which explicitly makes teaching an object of critical reflection and discussion. Our first seminar meeting addresses issues that are imminently-even urgently - practical ("In a few days you will be in front of students teaching a class here for the first time-what can we do to help you be prepared?"). At the same time we present teaching as a topic that is complex enough to approach theoretically. 
This attitude about teaching continues throughout the year and is reinforced through common readings, including McKeachie's Teaching Tips (McKeachie \& Svinicki, 2006) and Advice for New Faculty Members (Boice, 2000), both of which are given to each participant. ${ }^{6}$ One thing we do every year is to distribute a list of topics that the seminar has considered in prior years and ask the members to rank them in terms of their own interests. The survey not only gives the organizing committee a sense of the seminar members' concerns, it also orients the seminar members to the scholarly discussion of major topics in teaching and learning. During our monthly meetings, we address various issues related to teaching, such as assignment and course design, classroom incivilities, issues of power both inside and outside the classroom (including race and gender), active learning (discussion, group work), grading and evaluation, and student cultures and values (with students as guests). These issues correspond closely to the teaching topics that Seldin (2006) identifies as particularly relevant to a beginning faculty member's career. We also discuss topics related to college politics, power, promotion, and tenure, and offer seminar members additional opportunities for casual get-togethers, such as informal lunches and end-of-semester parties.

By incorporating second-and third-year faculty into the seminar each year as part of the organizing committee, the Johnson Seminar builds cohorts of faculty who have developed the habit of systematic reflection on their teaching practice; it sends the message that thinking about teaching should be an integral part of our work. Similar to the use of faculty learning communities to promote SoTL (Cox, 2003), our seminar creates a cross-cohort learning community that views teaching as critical practice. In addition, by incorporating a more experienced faculty fellow as a participant and by periodically drawing on the expertise and experience of other faculty members, the seminar connects beginning faculty members to senior faculty outside their departments and to the senior administration of the college, particularly the dean of the faculty. The seminar also puts participants into contact with the broader conversations about teaching and learning by providing funds to facilitate attendance and presentations at off-campus workshops and conferences that address teaching. Rather than offering participants a stipend paid in cash, the seminar gives money that is specifically earmarked to improve teaching.' This money closes the circle: We not only support teaching as a critical practice in theory, we also support faculty presenting on the topic of teaching or attending a conference focused on teaching (e.g., Association of American Colleges and Universities, POD, regional or disciplinary teaching conferences). Although a few administrators have questioned the wisdom of "paying" faculty to undertake something that is an essential part of their jobs 
and professional development (participating in this seminar and thinking about their teaching critically), we look at the "teaching credits" as the counterpart to the money Connecticut College offers its faculty to help them pursue their research-again, driving home the idea that small liberal arts colleges must support teaching as well as research.

Finally, the Johnson Seminar also encourages participants to apply for small grants from the CTL that will support projects related to the improvement and assessment of teaching.

In promoting SoTL, the Johnson Seminar has encountered a number of problems, not least of which is the question "Just what constitutes SoTL anyway?" There are some explicit and implied differences of opinion on this issue both across and within disciplines, including variations in the forms SoTL takes and orientations of its practitioners. Some disciplines seem more amenable to SoTL, and this disciplinary attitude can be reflected at the departmental level as well. And even if a department or wider discipline is open to the notion of SoTL, the way in which such scholarship is practiced within disciplines varies widely (Huber, 2004; Huber \& Morreale, 2002). The variations among disciplines, not to mention the range of attitudes displayed by departments representing those disciplines on a local level, make any discussion of SoTL with a general audience even more challenging because the procedures, standards, and even the way in which such work is valued often change from discipline to discipline.

The scholarship of teaching and learning also takes a variety of forms, representing a range of approaches to making teaching and learning an object of critical study, sometimes cven within the same discipline. Consequently, even those who would engage in SoTL have to negotiate within and between local tensions (my own classroom and practice, my own college) and global tensions (the field of SoTL, teaching in U.S. higher education). How one conceives of the task of SoTL and the models one encounters may make entry into SoTL appear either easier or more difficult.

New faculty may justifiably wonder how much SoTL actually matters to them as teachers, to their reappointment, tenure and promotion, to their senior colleagues in their department and on personnel committees. Such questions are particularly pressing to those in the pre-tenure phase of their carecrs. They have to consider whether the payoff from engaging in SoTL will be worth the investment, particularly when reflecting on their teaching seems inevitably to take time away from actually preparing for class, scholarly research, and the myriad service small college life requires (Gibson, 1992). Yet if we return to Shulman's definition of So'TL-simply "capturing teaching in a manner that makes it possible for others both to review it critically and to 
build on it themselves" (Carnegie Foundation, 1999) - then any responsible faculty member should continually be involved in critical reflection and the sharing of his or her teaching, at least at the local level. When Shulman (1999) examines the different ways in which students fail to learn, he directly links the solution to SoTL. Shulman (1999) calls for "a systematic approach" to help faculty cope with student failure to learn, and urges that "we must commit ourselves professionally to the scholarship of teaching" (p. 15). ${ }^{8}$ In other words, the scholarship of teaching leads to better student learning, making such critical practice a necessary activity at any institution that values student learning. Hall (2002) decries what he sees as the artificial boundaries between scholarship and teaching, and also between individual work and collaboration. Our seminar challenges such divisions, encourages faculty to think critically about their teaching, and gives participants a way to maintain an engagement with SoTL.

From our work with the Johnson Seminar, we have distilled several suggestions about how to promote a small college campus culture that values the scholarship of teaching and learning.

\section{Use Brokers}

At Connecticut College, the director of the CTL and, to a lesser extent, the faculty fellow, are directly and continually engaged with SoTL. They maintain a baseline flow of information, review the literature, attend conferences, attend and conduct workshops, and generally maintain a high level of participation in the growing field of the study of teaching and learning. We believe it is essential to have a central clearinghouse for information about SoTL and a dedicated person or persons who sifts through it and funnels what is relevant to the appropriate audiences; this switching function is probably the most important element in creating a local culture that values SoTL. For the Johnson Seminar, these leaders serve as trustworthy brokers; they distill what's out there, put people in touch with thoroughly evaluated resources, keep an eye on the literature, and generally try to bring to the attention of the seminar members precisely what will be helpful to them and only what will be helpful to them. In addition, they keep an eye on which faculty are involved in SoTL and bring to the seminar both past seminar graduates and more senior faculty who have been doing interesting work in the SoTL.

\section{Move incrementally}

The Johnson Seminar has adopted a wide view of SoTL. Its first goal is simply to get the participants talking with each other about their teaching. Beyond 
that, it aims to develop a system of reciprocal, nonevaluative, classroom observations in order to provide members with critical but sympathetic feedback on their teaching in addition to formal student and departmental evaluations. In addition, the seminar encourages participants to make lowstakes presentations on campus, either within the seminar itself or at other venues such as regular brown-bag "Talking Teaching" lunches. Further, the seminar encourages participants to attend nearby off-campus conferences and workshops as a group in order to become involved in broader conversations about teaching and learning.

\section{Take the Long View}

The Johnson Seminar encourages participants to plan for the medium to long term. It is designed to have faculty in their first three years maintain a steady - even if low-level of engagement with SoTL; they may, for example, start to file away ideas that they can take up again during their summers, on their fourth-year sabbaticals, or even on their post-tenure sabbaticals. The basic goal of the seminar is for participants to keep on their radar the idea that teaching can serve as an object of scholarly reflection. We hope that training in the fundamental elements of SoTL will bear fruit later in their careers. Indeed, we would argue that such early training prepares faculty for the inevitable career cycles we all experience. Our main focuses may fluctuate as our career progresses, sometimes emphasizing research, sometimes concentrating on teaching, and sometimes focusing on service. Thus, taking the long view of SoTL is essential, and preparing faculty to undertake such work is clearly the precursor for doing such work."

\section{Take Boyer's Calegories of Scholarship Seriously}

Faculty members arrive on campus ready, willing, and eager to pursue the scholarship of discovery. Some become interested in the scholarship of application, and others the scholarship of synthesis. Very few have seriously contemplated undertaking the scholarship of teaching in any form. The seminar encourages participants to find their own niches while being aware of other possibilities, to contemplate the rhythms and shifts of scholarly interests over a long career, and to reject the notion that they will have to or need to undertake all four types of scholarship with equal commitment and intensity at the same time. ${ }^{10}$ The seminar acknowledges that simply staying aware of SoTL may be sufficient for certain periods during a long carcer or even for the entire career, so long as it promotes reflective practice. 
One of the reasons that the Johnson Seminar has been successful is that it doesn't overreach. Successive organizing committees have developed a solid sense of what the seminar can and cannot do for its participants. It has been demonstrably successful in promoting and sustaining at least a minimal continuing engagement with SoTL among its graduates. By doing that, it has incrementally adjusted our own campus culture to promote SoTL. It has supported individual projects in SoTL by providing small grants, a pool of collaborators, and a sympathetic audience. It showcases local, on-campus SoTL both in the actual seminar meetings and in other programs of the Connecticut College CTL. By not requiring of faculty a certain level or kind of engagement with SoTL-beyond making their teaching public practice by sharing their teaching materials, challenges, and successes within the confines of the seminar-the seminar has helped participants to discover and pursue their own interests in reflective practice. The results of that culture of encouragement can be seen in the seminar graduates who have gone on to offer oncampus workshops and other presentations on a variety of pedagogical topics ranging from teaching critical thinking skills across the curriculum to running effective discussions, from the challenges and philosophy of grading to the effective use of technology, from incorporating information fluency assignment to diversity in the classroom.

\section{Evidence of a Culture of Teaching and learning}

The Johnson Seminar has begun to transform the overall culture of teaching on campus. Before the founding of our Center for Teaching and Learning and the establishment of the seminar, there was no systematic attention paid to teaching and no formal mechanism for tracking faculty participation in the scholarship of teaching and learning. Although we can offer no baseline statistics for So'TL, there are some indicators of success for the seminar.

- Since 2000 , more than $90 \%$ of the first-year faculty return for a second year to help facilitate the seminar for the new group of incoming faculty. Approximately $25 \%$ of those return for a third year.

- The number of participants who have attended conferences and workshops related to teaching and learning-or have presented on a teachingrelated topic at a disciplinary conference-has been steadily rising.

- The number of participants who have themselves offered on-campus workshops continues to grow, as does the willingness of former participants to take on such work when they are asked to do so. At least one of 
these campus workshops-on teaching students critical thinking skillsled to the faculty member writing an article on the topic in a widely distributed, national periodical that addresses teaching.

- Participants have included a number of teaching-related publications in the review files for third-year and tenure reviews, and the CTL and the Johnson Seminar in particular are prominent in faculty personal statements for these reviews."

Additionally, interdisciplinary work related to teaching has flourished through connections and bonds formed through the seminar. For example, former seminar participants created an interdisciplinary course on modernism, team-taught by untenured faculty from across a variety of departments. The following year the two faculty who coordinated that course organized and ran a faculty seminar on interdisciplinarity, and arising out of that seminar, there have been faculty seminars on the state of cultural theory and living a moral life.

The 2004-2005 academic year was the first in which a full group of Johnson Seminar graduates came up for tenure. As these colleagues advance in their careers, they will infuse the school's decision-making processes with their own values. We expect, for example, as those recently tenured colleagues begin to evaluate their untenured colleagues for promotion and tenure, they will bring with them an understanding of teaching as a process worthy of critical consideration. The work done on SoTL by new candidates for promotion and tenure will get the consideration it deserves. This will encourage more faculty to take teaching as a form of scholarship more seriously. The cultural shift toward valuing teaching and learning makes a complete loop and becomes self-perpetuating. We would also argue that the Johnson Seminar models a collaborative spirit that can be easily transferred to other group undertakings, such as committee work. ${ }^{12}$ Finally, faculty who have shared syllabi and assignments, who have been in each other's classrooms, and who know of each other's teaching successes and failures, make for sympathetic and empathetic colleagues.

It is essential for small liberal arts colleges to dedicate the resources-financial and personncl-to promoting the critical discussion of teaching. As the study of teaching and learning as a discipline expands, such schools can no longer get away with giving mere lip service to valuing teaching. Small libcral arts colleges must vigorously pursue and actively promote excellence in tcaching.

In order for SoTL ever to be valued on a campus, a campus culture must explicitly value teaching by devoting time, energy, and money to its 
development. Merely "valuing teaching," a mantra at many small liberal arts college, is simply not enough. While the more time-intensive and even technical SoTL may not be appropriate (or even of interest) to all faculty, it is imperative that colleges provide the means and impetus for faculty to engage in SoTL at a local level. By introducing teaching as something intentional and deliberate-worthy of discussion and critical examination-our seminar has created a culture that not only explicitly values teaching, but also has begun to implicitly and explicitly engage in the scholarship of teaching and learning.

Our peer-mentoring model was created out of the exigencies particular to the setting of a small liberal arts college: in terms of scale and in terms of the need for faculty to form supportive networks beyond their often small departments or buildings. However, this model, which emphasizes multiple faculty connections that cross disciplines and cohorts, has helped bring about a major cultural shift on our campus. At Connecticut College, teaching truly has become community property.

\section{Acknowledgments}

We would like to thank the Christian A. Johnson Endeavor Foundation for their generous support of the Center for Teaching and Learning and the Johnson Teaching Seminar for Incoming Faculty. A version of this chapter was presented at the conference "Innovations in the Scholarship of Teaching and Learning at Liberal Arts Colleges" sponsored by Carleton College and St. Olaf College, April 1-3, 2005. We would also like to thank David Schodt, director of St. Olaf's Center for Innovation in the Liberal Arts and conference co-chair, for his encouragement and help in shaping our original proposal.

C 2006 Michael Reder and Eugene V. Gallagher.

\section{Endnotes}

1) Since 1999, the Christian A. Johnson Endeavor Foundation has funded the teaching seminar and the majority of our Center for Teaching and Learning through two generous grants.

2) Of course, syllabi vary in content and construction, and this might shape the amount they reveal about a person's teaching. A well-constructed syllabus can reveal more than a minimalist syllabus that is little more than a course schedule-although a minimalist syllabus is revelatory in its own way. For example, a syllabus can reveal what the faculty member values and emphasizes (by how the course 
weighs the variety of assignments when assigning a final grade), a faculty member's attitude toward grading and learning as a process, how he or she views the construction of knowledge, and hoped-for outcomes in terms of student learning (when a list of learning goals is included). The documents that the teaching seminar uses for its syllabus review workshop can be downloaded at http://CTL.ConnColl.edu/ resources/syllabusworkshop/

3) Although the faculty fellow takes part in this workshop, his role has been as a source for information and informed opinion, as someone who possesses a strong institutional memory. Much of the success of this seminar has to do with the willingness of the faculty fellow to be the proverbial "guide on the side" rather than the "sage on the stage." His syllabus is also reviewed, and he makes it clear from the beginning that he regularly "steals" ideas and assignments from those participating in the seminar.

4) Inviting second-and third-year faculty back to facilitate the teaching seminar helps address another challenge that such first-year seminars face on small college campuses: uneven hiring from year to year. Since 1997, Connecticut College has hired anywhere from 1 to 11 new tenure-track faculty members; in some years there are too few new faculty hired to compose an active seminar (an issue not faced at larger institutions). By allowing faculty from other recent cohorts to participate, we ensure there are always enough faculty, in terms of both number and diversity, to make the seminar work.

5) It is important to note that most small liberal arts colleges are "known" for the quality of their teaching because that is the way in which they present and market thenselves, often without persuasive substantiation.

6) In addition to these two books, we also provide specific articles related to the current topic under discussion. Although these are constantly changing, for a seminar meeting with the topic of "Making Our Classrooms Active," we might ask faculty to read a few chapters in McKeachie's Tenching Tips (McKeachie \& Svinincki, 2006), and then provide short articles on running discussion (e.g., Frederick, 1981) and making lectures more effective (e.g., Desrochers 1999). Visit http://CTL.ConnColl.edu/ bibliographies/ for a current bibliography of seminar readings listed by topic.

7) Visit http://CTL.ConnColl.edu/TeachingBank.html for a full explanation of how these "teaching credits" may be used and the varying amounts allotted to seminar participants.

8) It is important to note that for Shulman (1999)

All acts of intelligence are not scholarship. An act of intelligence or of artistic creation becomes scholarship when it possesses at least three attributes: it becomes public; it becomes an object of critical review and evaluation by members of one's community; and members of one's community begin to usc, build upon, and develop those acts of mind and creation. (p. 15) 
9) The idea of engaging teaching at certain points in one's career seems to be working on our campus. Two faculty members recently granted tenure have decided that their next major projects will be teaching related: One had applied for outside funding to totally rethink her department's introductory course to the major; another has begun to study how discussion functions to advance knowledge in his classroom.

10) In Scholarship Reconsidered, Boyer (1990) identifies, in addition to the scholarship of teaching, three additional types of scholarship: discovery, integration, and application. According to Boyer, the scholarship of discovery "comes closest to what is meant when academics speak of 'research' " $(p .17)$. The scholarship of integration involves "making connections across the disciplines, placing the specialties in larger context, illuminating data in a revealing way, often educating nonspecialists, too" ( $p$. 18). The scholarship of application asks and attempts to answer questions like "How can knowledge be responsibly applied to consequential problems?" "How can it be helpful to individuals and institutions?" and even "Can social problems themselves define an agenda for scholarly investigation?" (p. 21). Boyer argues that "What we urgently need today is a more inclusive view of what it means to be a scholar-a recognition that knowledge is acquired through research, through synthesis, through practice, and through teaching" (p. 24). It is important to understand that while Boyer divides scholarship into four separate categories for the purpose of discussion and analysis, he believes that as "intellectual functions" they are "tied inseparably to each other" (p. 25).

11) The Johnson Seminar started attracting the attention-not to mention strong support-of the dean of the faculty when, during her end-of-year interviews with first-year faculty, the seminar was consistently mentioned by those faculty as one of the best things about their first year at Connecticut College. As the positive reports continued, the dean's office started using the Johnson Seminar to help attract new faculty hires. The CTL brochure is the only brochure on the coffee table where the dean conducts her interviews. It is also worth noting that participating in the Johnson Scminar is voluntary: Since 1999, it has boasted $100 \%$ participation by incoming faculty, including faculty who arrive with years of teaching experience, faculty coming in at the associate level with tenure, and even full professors holding named chairs.

12) Interestingly, the Johnson Seminar has been identified, sometimes resentfully, among senior tenured colleagues, as a center for political power on campus, as a means by which newer faculty have connected with each other to empower untenured faculty in ways they had not previously been empowered. 


\section{References}

Boice, R. (1991, January). New faculty as colleagues. International Journal of Qualitative Studies in Education, 4(1), 29-44.

Boice, R. (1992). The new faculty member: Supporting and fostering professional development. San Francisco, CA: Jossey-Bass.

Boice, R. (2000). Advice for new faculty members: Nihil nimus. Needham Heights, MA: Allyn \& Bacon.

Boyer, E. L. (1990). Scholarship reconsidered: Priorities of the professoriate. Princeton, N): Carnegie Foundation for the Advancement of Teaching.

Carnegie Foundation for the Advancement of Teaching (Producer). (1999). Fostering a scholarship of teaching [Film]. Oregon: West Peak Media.

Cox, M. D. (2001). Faculty learning communities: Change agents for transforming institutions into learning organizations. In D. Lieberman \& C. Wehlburg (Eds.), To improve the academy: Vol. 19. Resources for faculty, instructional, and organizational development (pp. 69-93). Bolton, MA: Anker.

Cox, M. D. (2003). Proven faculty development tools that foster the scholarship of teaching in faculty learning communities. In C. M. Wehlburg \& S. ChadwickBlossey (Eds.), To improve the academy: Vol. 21. Resources for faculty, instructional, and organizational development (pp. 109-142). Bolton, MA: Anker.

Desrochers, C. (1999, December). Multi-purpose lecture breaks. The Teaching Professor, 13(10), 1-2.

Fayne, H., \& Ortquist-Ahrens, L. (2006). Learning communities for first-year faculty: Transition, acculturation, and transformation. In S. Chadwick-Blossey \& D. R. Robertson (Eds.), To improve the academy: Vol. 24. Resources for faculty, instructional, and organizational development (pp. 277-290). Bolton, MA: Anker.

Frederick, P. (1981, Summer). The dreaded discussion: Ten ways to start. Improving College and University Teaching, 29(3), 109-114.

Gibson, G. W. (1992). Good start: A guidebook for new faculty in liberal arts colleges. Bolton, MA: Anker.

Hall, D. E. (2002). The academic self: An owner's manual. Columbus, OH: The Ohio State University Press.

Holmgren, R., Mooncy, K., \& Reder, M. (2005, January). Transforming tcaching cultures: The need for teaching and learning programs at liberal arts colleges. Paper presented at the annual meeting of the Association of American Colleges and Universities, San Francisco, CA. 
Huber, M. T. (2004). Balancing acts: The scholarship of teaching and learning in academic careers. Sterling, VA: Stylus.

Huber, M. T., \& Morreale, S. P. (Eds.). (2002). Disciplinary styles in the scholarship of teaching and learning: Exploring common ground. Washington, DC: American Association for Higher Education.

McKeachie, W. J., \& Svinicki, M. (2006). McKeachie's teaching tips: Strategies, research, and theory for college and university teachers (12th ed.). Boston, MA: Houghton Mifflin.

Menges, R. J. (1996). Experiences of newly hired faculty. In L. Richlin \& D. DeZure (Eds.), To improve the academy: Vol. 15. Resources for faculty, instructional, and organizational development (pp. 169-182). Stillwater, OK: New Forums Press.

Menges, R. J., \& Associates. (1999). Faculty in new jobs: A guide to settling in, becoming established, and building institutional support. San Francisco, CA: Jossey-Bass.

Otto, M. L. (1994). Mentoring: An adult developmental perspective. In M. A. Wunsch (Ed.), New directions for teaching and learning: Vol. 57. Mentoring revisited: Making an impact on individuals and institutions (pp. 15-24). San Francisco, CA: Jossey-Bass.

Rice, R. E., Sorcinelli, M. D., \& Austin, A. E. (2000). Heeding new voices: Academic careers for a new generation. Washington, DC: American Association for Higher Education.

Seldin, P. (2006). Tailoring faculty development programs to faculty career stages. In S. Chadwick-Blossey \& D. R. Robertson (Eds.), To improve the academy: Vol. 24. Resources for faculty, instructional, and organizational development (pp. 137-146). Bolton, MA: Anker.

Shulman, L. S. (1999, July/August). Taking learning seriously. Change, 31(4), 10-17.

Smith, K. S., \& Kalivoda, P. L. (1998). Academic morphing: Teaching assistant to faculty member. In M. Kaplan \& D. Lieberman (Eds.), To improve the academy: Vol. 17. Resources for faculty, instructional, and organizational development (pp. 85-101). Stillwater, OK: New Forums Press.

Wheeler, D. W., \& Wheeler, B. J. (1994). Mentoring faculty for midcareer issues. In M. A. Wunsch (Ed.), New dirctions for teaching and learning: Vol. 57. Mentoring revisited: Making an impact on individuals and institutions (pp. 91-98). San Francisco, CA: Jossey-Bass.

Wright, W. A. (Ed.). (1995). Teaching improvement practices: Successful strategies for higher educationn. Bolton, MA: Anker. 